\title{
Pilot Study of a New Device to Titrate Oxygen Flow in Hypoxic Patients on Long-Term Oxygen Therapy
}

\author{
Serena Cirio FT and Stefano Nava MD
}

\begin{abstract}
BACKGROUND: The $\mathrm{O}_{2}$ Flow Regulator (Dima, Bologna, Italy) is a new automated oxygen regulator that titrates the oxygen flow based on a pulse-oximetry signal to maintain a target $\mathrm{S}_{\mathrm{pO}_{2}}$. We tested the device's safety and efficacy. METHODS: We enrolled 18 subjects with chronic lung disease, exercise-induced desaturation, and on long-term oxygen therapy, in a randomized crossover study with 2 constant-work-load 15-min cycling exercise tests, starting with the patient's previously prescribed usual oxygen flow. In one test the oxygen flow was titrated manually by the respiratory therapist, and in the other test the oxygen flow was titrated by the $\mathrm{O}_{2}$ Flow Regulator, to maintain an $\mathrm{S}_{\mathrm{pO}_{2}}$ of $94 \%$. We measured $\mathrm{S}_{\mathrm{pO}_{2}}$ throughout each test, the time spent by the respiratory therapist to set the device or to manually regulate the oxygen flow, and the total number of respiratory-therapist titration interventions during the trial. RESULTS: There were no differences in symptoms or heart rate between the exercise tests. Compared to the respiratory-therapistcontrolled tests, during the $\mathrm{O}_{2}$ Flow Regulator tests $\mathrm{S}_{\mathrm{pO}_{2}}$ was significantly higher $(95 \pm 2 \%$ vs $93 \pm 3 \%, P=.04)$, significantly less time was spent below the target $\mathrm{S}_{\mathrm{pO}_{2}}(171 \pm 187 \mathrm{~s}$ vs $340 \pm 220 \mathrm{~s}, P<.001$ ), and the $\mathrm{O}_{2}$ Flow Regulator tests required significantly less respiratory therapist time (5.6 $\pm 3.7 \mathrm{~min}$ vs $2.0 \pm 0.1 \mathrm{~min}, P=.005)$. CONCLUSIONS: The $\mathrm{O}_{2}$ Flow Regulator may be a safe and effective alternative to manual oxygen titration during exercise in hypoxic patients. It provided stable $\mathrm{S}_{\mathrm{pO}_{2}}$ and avoided desaturations in our subjects. Key words: long-term oxygen therapy; oxygen; COPD; $S_{p_{2}}$; oximetry; exercise test. [Respir Care 2011;56(4):429-434. ( 2011 Daedalus Enterprises]
\end{abstract}

\section{Introduction}

Long-term oxygen therapy (LTOT) has been a standard treatment for patients with COPD and chronic respiratory

\footnotetext{
Serena Cirio FT is affiliated with the Pulmonary and Critical Care Unit, Fondazione Salvatore Maugeri, Istituto di Ricovero e Cura a Carattere Scientifico, Istituto Scientifico di Pavia, Italy. At the time of this research, Stefano Nava MD was also affiliated with the Pulmonary and Critical Care Unit, Fondazione Salvatore Maugeri, IRCCS, Istituto Scientifico di Pavia, Italy. He is now affiliated with Pneumologia e Terapia Intensiva Respiratoria, Dipartimento Cardio-Toraco-Vascolare, Policlinico Sant' Orsola-Malpighi, Bologna, Italy.
}

Ms Cirio has disclosed a relationship with Vivisol. Dr Nava has disclosed no conflicts of interest.

Correspondence: Stefano Nava MD, Pneumologia e Terapia Intensiva Respiratoria, Policlinico Sant Orsola-Malpighi, via Massarenti n.9, Bologna 40138 Italy. E-mail: stefano.nava@aosp.bo.it.

DOI: $10.4187 /$ respcare.00983 failure since the 1970s, when it was found that LTOT can improve survival. ${ }^{1,2}$ Indications for LTOT are accepted worldwide, and international guidelines recommend LTOT if the patient's resting $\mathrm{P}_{\mathrm{aO}}$ is $<55 \mathrm{~mm} \mathrm{Hg}$, or $55-59 \mathrm{~mm} \mathrm{Hg}$ if there is evidence of right-atrial enlargement, congestive heart failure, and high hematocrit $(>55 \%))^{3-5}$ There is overall agreement that a $\mathrm{P}_{\mathrm{aO}_{2}}>60 \mathrm{~mm} \mathrm{Hg}$ is the goal of

See the Related Editorial on Page 536

LTOT, to enhance peripheral oxygenation. ${ }^{6,7}$ The indications for LTOT in patients with exercise-induced desaturation are still controversial. Some studies have found an $\mathrm{S}_{\mathrm{pO}_{2}}$ drop despite supplemental oxygen during mild exercise, sleep, and usual activities of daily living. ${ }^{8-10}$

Recent guidelines on pulmonary rehabilitation emphasize the importance of COPD patients, including those with chronic respiratory failure, maintaining an active life, and an exercise program for the muscles of ambulation is 


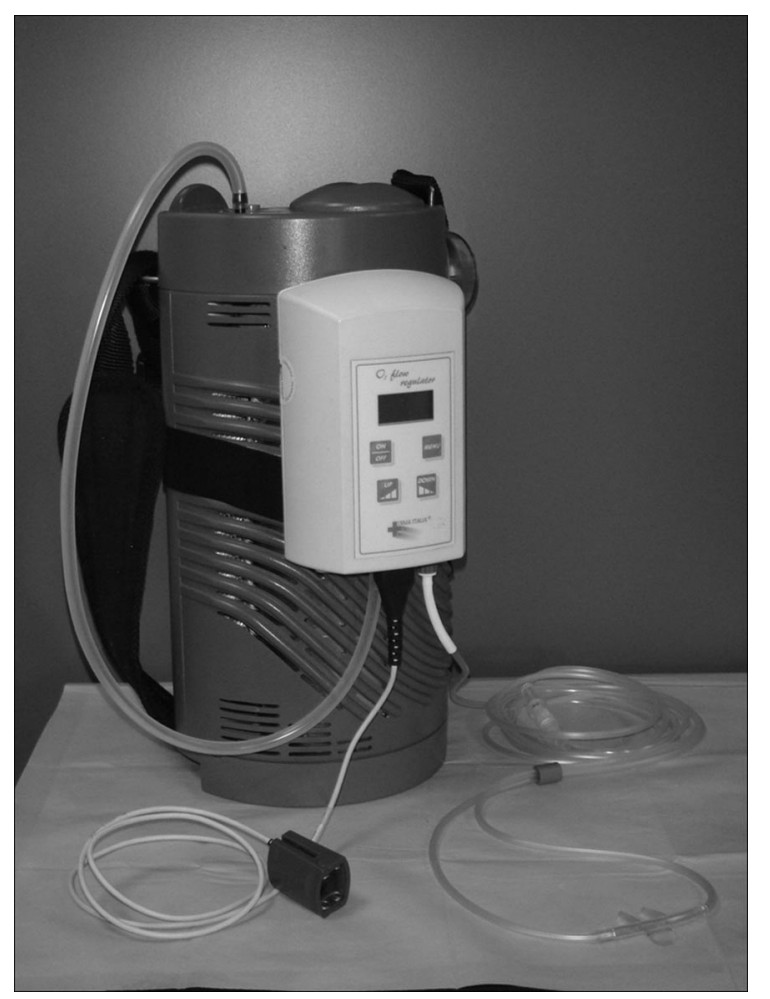

Fig. 1. $\mathrm{O}_{2}$ Flow Regulator, Dima, Bologna, Italy, which is currently only available in Italy.

recommended as a main component of pulmonary rehabilitation. ${ }^{11}$

Different types of exercise produce different levels of desaturation, ${ }^{12-14}$ so the commonly prescribed fixed oxygen flow, which is usually titrated at rest, may not meet every patient's need. It would be preferable, therefore, to regulate the oxygen flow according to the patient's actual, changing need. A new automatic $\mathrm{O}_{2}$ flow-regulator device, the $\mathrm{O}_{2}$ Flow Regulator (Dima, Bologna, Italy, distributed by Vivisol, Monza, Italy) was recently released (Fig. 1). Its primary function is to titrate the oxygen flow rate based on a pulse-oximetry signal, to maintain a target $\mathrm{S}_{\mathrm{pO}_{2}}$.

We conducted a pilot randomized crossover study to evaluate the safety and efficacy of the $\mathrm{O}_{2}$ Flow Regulator, compared to usual manual oxygen flow titration.

\section{Methods}

\section{Patients}

We recruited 18 consecutive clinically stable COPD patients on LTOT from the patients attending a pulmonary rehabilitation program. The inclusion criteria were hypoxia at rest $\left(\mathrm{P}_{\mathrm{aO}_{2}}<55 \mathrm{~mm} \mathrm{Hg}\right.$ on room air $)$ and exerciseinduced desaturation when using their usual prescribed oxygen flow. The usual oxygen flow is prescribed based on a mean $\mathrm{S}_{\mathrm{pO}_{2}} \leq 88 \%$ during a 6 -min walk test, and reassessment the next day during a 15 -min constant-exercise cycle-ergometer test, at the same oxygen flow. We excluded patients who had chronic heart failure or any other cardiopathy, atrial fibrillation, neurological disease, or difficulty in cycling; who needed an $\mathrm{O}_{2}$ flow of $>6 \mathrm{~L} /$ min at rest; whose carboxyhemoglobin was $>4 \%$; or whose methemoglobin was $>1 \%$. This study was approved by the Comitato Etico Centrale of Fondazione Salvatore Maugeri, and we obtained written informed consent from each subject.

\section{Study Design}

The study was a randomized controlled crossover trial. In each subject, during 2 standardized 15-min cycling tests, we measured $\mathrm{S}_{\mathrm{pO}_{2}}$, respiratory therapist (RT) time (to set or adjust the devices), and the total number of RT interventions. On 2 consecutive days, each subject performed, in random order, and using the same oxygen source (portable liquid oxygen cylinder, filled and calibrated before every test, with a maximum flow rate of $6 \mathrm{~L} / \mathrm{min}$ ), the exercise test with an individualized stable work load that was selected on the basis of 2 previous exercise tests that determined the maximum exercise load the patient could sustain without needing to pause, while using their prescribed oxygen flow. During the tests the patients were monitored continuously with a 3-lead electrocardiogram and pulse oximetry (Pulsox-3iA, Konica Minolta Sensing, Ramsey, New Jersey) with a finger probe. A priori we chose a target $\mathrm{S}_{\mathrm{pO}_{2}}$ of $94 \% .{ }^{15}$ The randomization order was decided with opaque sealed envelopes.

\section{$\mathrm{O}_{2}$ Flow Regulator}

The $\mathrm{O}_{2}$ Flow Regulator was developed to automatically titrate the $\mathrm{O}_{2}$ flow to maintain a constant $\mathrm{S}_{\mathrm{pO}_{2}}$ (Fig. 2). It is placed in line between an oxygen source and the user. Once the clinician sets the target $\mathrm{S}_{\mathrm{pO}_{2}}$, the device should be able to maintain it, increasing or decreasing the flow for any $\mathrm{S}_{\mathrm{pO}_{2}}$ variation above or below the target. A microprocessor continuously reads the $\mathrm{S}_{\mathrm{pO}_{2}}$ signal; if $\mathrm{S}_{\mathrm{pO}_{2}}$ is lower than the target, it rapidly opens the flow valve $(2 \mathrm{~L}$ change over $30 \mathrm{~s}$ ) to increase oxygen delivery. If $\mathrm{S}_{\mathrm{pO}_{2}}$ exceeds the target, the valve slowly closes $(0.5 \mathrm{~L}$ change over $30 \mathrm{~s})$ to reduce the flow.

\section{Protocol}

Each subject performed 2 exercise tests: one in which the RT manually titrated the oxygen flow (the RT-controlled test), and one in which the $\mathrm{O}_{2}$ Flow Regulator titrated the oxygen flow (the $\mathrm{O}_{2}$ Flow Regulator test) un- 


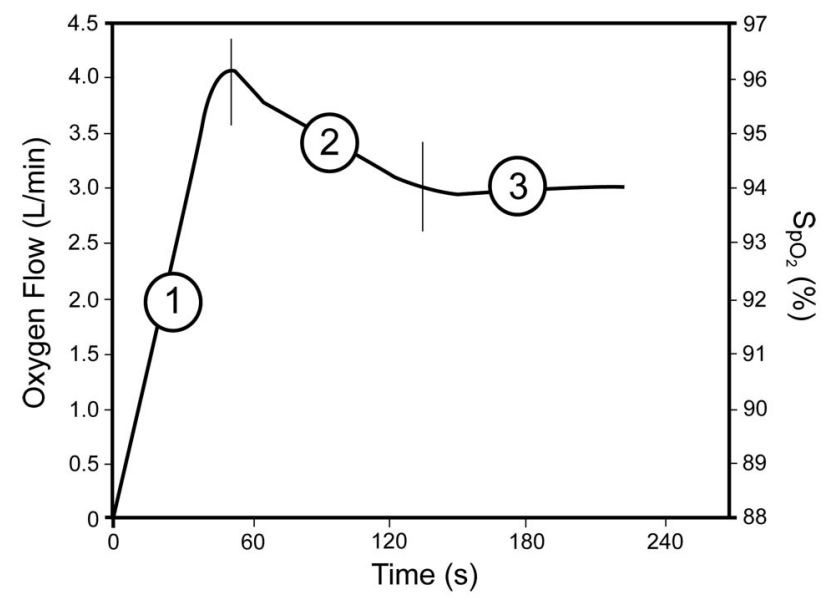

Fig. 2. $\mathrm{O}_{2}$ Flow Regulator response to $\mathrm{S}_{\mathrm{pO}_{2}}$ variation. At point 1, $\mathrm{S}_{\mathrm{pO}_{2}}$ is below the target $\mathrm{S}_{\mathrm{pO}_{2}}$, and the $\mathrm{O}_{2}$ Flow Regulator valve rapidly opens and increases the oxygen flow. At point $2 \mathrm{~S}_{\mathrm{pO}_{2}}$ is above the target $\mathrm{S}_{\mathrm{pO}_{2}}$ and the $\mathrm{O}_{2}$ Flow Regulator valve slowly closes and decreases the oxygen flow. At point 3 the $\mathrm{S}_{\mathrm{pO}_{2}}$ is at the target, so the $\mathrm{O}_{2}$ Flow Regulator maintains the current oxygen flow.

der the supervision of the same RT. During the RT-controlled test, to simulate the behavior of the $\mathrm{O}_{2}$ Flow Regulator, the RT titrated the oxygen flow rate every one minute, as necessary to achieve the target $\mathrm{S}_{\mathrm{pO}_{2}}$, with the same flow-change rates as the $\mathrm{O}_{2}$ Flow Regulator.

We measured dyspnea and leg fatigue with the modified Borg scale, every minute. The oximeter calculated the mean $\mathrm{S}_{\mathrm{pO}_{2}}$ during the test and the time spent with $\mathrm{S}_{\mathrm{pO}_{2}}<94 \%$.

We counted the number of RT interventions (titrations) during the RT-controlled test. An observer naïve to the protocol used a stopwatch to measure the RT time during the RT-controlled test, and, during the $\mathrm{O}_{2}$ Flow Regulator test, to measure the RT time to set the $\mathrm{O}_{2}$ Flow Regulator (ie, set the target $\mathrm{S}_{\mathrm{pO}_{2}}$ and alarms, and check the battery and memory card).

\section{Statistical Analysis}

We used a paired $t$ test to compare the data from the exercise tests. Data are presented as mean $\pm \mathrm{SD}$. A $P<.05$ was considered statistically significant.

\section{Results}

Table 1 shows the cohort's mean age, $\mathrm{P}_{\mathrm{aO}_{2}}, \mathrm{P}_{\mathrm{aCO}}, \mathrm{pH}$, baseline $\mathrm{S}_{\mathrm{pO}_{2}}$, and nadir $\mathrm{S}_{\mathrm{pO}_{2}}$ during exercise. All the patients tolerated well the experimental procedures and completed both tests. There was no statistical differences in dyspnea, leg fatigue, heart rate, or oxygen saturation at rest between the RT-controlled tests and $\mathrm{O}_{2}$ Flow Regulator tests (Table 2). Dyspnea, leg fatigue, and heart rate increased similarly. Mean $\mathrm{S}_{\mathrm{pO}_{2}}$ was significantly higher dur-
Table 1. Age and Arterial Blood Values Before the Exercise Tests*

\begin{tabular}{lc}
\hline \hline & Mean $\pm \mathrm{SD}$ \\
\hline Age $(\mathrm{y})$ & $69 \pm 8$ \\
$\mathrm{P}_{\mathrm{aO}_{2}}(\mathrm{~mm} \mathrm{Hg})$ & $69 \pm 9$ \\
$\mathrm{P}_{\mathrm{aCO}}(\mathrm{mm} \mathrm{Hg})$ & $45 \pm 8$ \\
$\mathrm{pH}$ & $7.42 \pm 0.04$ \\
$\mathrm{Baseline} \mathrm{S}_{\mathrm{pO}_{2}}(\%)$ & $95 \pm 2$ \\
Nadir $\mathrm{S}_{\mathrm{pO}_{2}}$ during 6MWT $(\%)$ & $86 \pm 4$ \\
& \\
* Arterial blood was sampled with the patient at rest while on his or her usual supplemental \\
oxygen flow (mean 1.6 $0.4 \mathrm{~L} /$ min). \\
6MWT = 6-min walk test with the patient's usual resting oxygen flow \\
\hline
\end{tabular}

ing the $\mathrm{O}_{2}$ Flow Regulator tests $(95 \pm 2 \%$ vs $93 \pm 3 \%$, $P=.04)$.

Figure 3 shows typical $\mathrm{S}_{\mathrm{pO}_{2}}$ traces from a representative patient during both the RT-controlled test and the $\mathrm{O}_{2}$ Flow Regulator test. Figure 4 shows the amount of time the subjects spent below the target $\mathrm{S}_{\mathrm{pO}_{2}}$. Overall, the $\mathrm{O}_{2}$ Flow Regulator tests had significantly less time below the target $\mathrm{S}_{\mathrm{pO}_{2}}(171 \pm 187 \mathrm{~s}$ vs $341 \pm 220 \mathrm{~s}, P<.001)$. During the $\mathrm{O}_{2}$ Flow Regulator tests only 2 of the 18 subjects had $\mathrm{S}_{\mathrm{pO}_{2}}$ decrease to $<90 \%$, and those desaturation periods were $<30$ s.

Figure 5 illustrates the number of manual titrations during the RT-controlled tests. The mean RT time was significantly greater in the RT-controlled tests $(5.6 \pm 3.7 \mathrm{~min}$ vs $2.0 \pm 0.1 \mathrm{~min}, P=.005$ ).

\section{Discussion}

The major international guidelines and position papers on prescription of LTOT are based either on resting or exertional $\mathrm{S}_{\mathrm{pO}_{2}}$, usually assessed during the 6-min walk test. ${ }^{3-16}$ However, at home some LTOT patients have severe desaturations during sleep or activities of daily living, that are not necessarily revealed during the 6-min walk test. ${ }^{17}$ This suggests that the oxygen flow should be constantly titrated. We found the $\mathrm{O}_{2}$ Flow Regulator safe and effective in meeting the target $\mathrm{S}_{\mathrm{pO}_{2}}$. The $\mathrm{O}_{2}$ Flow Regulator tests had significantly less time below the target $\mathrm{S}_{\mathrm{pO}_{2}}$. We chose our target $\mathrm{S}_{\mathrm{pO}_{2}}$ on the basis of a study that found that an $\mathrm{S}_{\mathrm{pO}_{2}}$ of $\geq 93 \%$ should be the objective during exercise in patients who desaturate during exercise. ${ }^{15}$

There are several reasons an in-line oxygen flow regulator may be useful in LTOT patients. First, studies have found that, when reevaluating patients' LTOT requirement after the initial prescription, many patients no longer meet the LTOT eligibility criteria or that they need to have the oxygen flow reduced, mostly because they were recovering from an exacerbation. ${ }^{18}$ The $\mathrm{O}_{2}$ Flow Regulator can decrease the oxygen flow to zero if the target $\mathrm{S}_{\mathrm{pO}_{2}}$ is being met without oxygen flow, which is particularly important 
Table 2. Symptoms, Mean $\mathrm{S}_{\mathrm{pO}_{2}}$, and Heart Rate, at Rest and During Exercise

\begin{tabular}{|c|c|c|c|c|}
\hline & $\begin{array}{l}\text { At-Rest Before the } \\
\text { RT-Controlled Test }\end{array}$ & $\begin{array}{l}\text { At-Rest Before the } \mathrm{O}_{2} \\
\text { Flow Regulator Test }\end{array}$ & RT-Controlled Test & $\begin{array}{c}\mathrm{O}_{2} \text { Flow } \\
\text { Regulator Test }\end{array}$ \\
\hline Borg dyspnea score & $0.8 \pm 1.1$ & $1.0 \pm 1.2$ & $3.2 \pm 1.4^{*}$ & $2.9 \pm 1.0^{*}$ \\
\hline Borg leg fatigue score & $0.5 \pm 1.0$ & $0.8 \pm 1.4$ & $3.1 \pm 1.5^{*}$ & $3.0 \pm 1.8^{*}$ \\
\hline Heart rate (beats/min) & $83 \pm 10$ & $83 \pm 9$ & $100 \pm 4^{*}$ & $96 \pm 12 *$ \\
\hline Mean $\mathrm{S}_{\mathrm{pO}_{2}}(\%)$ & $92 \pm 3$ & $92 \pm 3$ & $93 \pm 3 \dagger$ & $95 \pm 2 \dagger \neq$ \\
\hline \multicolumn{5}{|c|}{$\begin{array}{l}\text { * At the end of the exercise test. } \\
\dagger \mathrm{Mean} \mathrm{S}_{\mathrm{pO}_{2}} \text { during the exercise test. } \\
\ddagger P=.046\end{array}$} \\
\hline
\end{tabular}

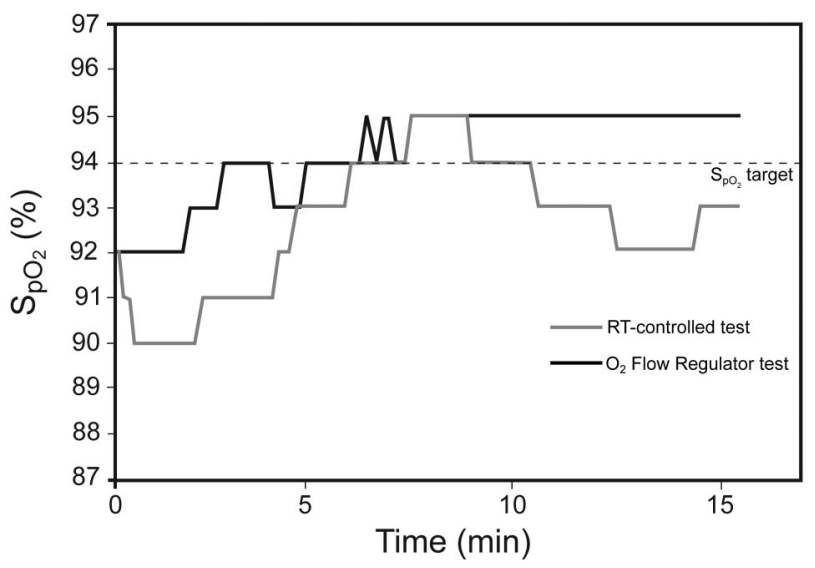

Fig. 3. Typical $\mathrm{S}_{\mathrm{pO}_{2}}$ traces from a representative patient during exercise tests in which the supplemental oxygen flow was manually titrated by the respiratory therapist (RT) or automatically titrated by the $\mathrm{O}_{2}$ Flow Regulator.

in patients with hypercapnia, because increasing $\mathrm{P}_{\mathrm{aO}}$ in a patient with hypercapnic respiratory failure causes deleterious changes to alveolar ventilation and gas exchange, which worsens acidosis, and increases morbidity and mortality. ${ }^{19}$

Second, it has been suggested that long-term rehabilitation programs may be useful in COPD patients, with or without chronic respiratory failure. ${ }^{11}$ Among the various rehabilitation activities, high-intensity training is more effective in improving exercise capacity, and supplemental oxygen increases exercise ability, allowing higher exercise intensity, in COPD patients without resting hypoxemia who desaturate during exercise. ${ }^{20}$ This highlights the importance of oxygen flow titration for these patients during rehabilitation at home, especially considering that their clinical status may deteriorate.

Third, few studies have recorded $\mathrm{S}_{\mathrm{pO}_{2}}$ over a 24-hour period in COPD patients, either receiving LTOT or not, and both groups manifest severe desaturations during sleep and activities of daily living. ${ }^{8-10}$ Walking is usually associated with the lowest mean $\mathrm{S}_{\mathrm{pO}_{2}}$ and with the highest number of desaturations, which are particularly severe in some individuals. However, eating, washing, house-work, dressing, and even watching television are activities of daily living that are associated with frequent desaturations, in certain cases even worse than during walking. Some patients may spend $>30 \%$ of the day with $\mathrm{S}_{\mathrm{pO}_{2}}$ below 90\%. ${ }^{8-10}$ These desaturation episodes are dangerous, because they may transiently increase the mean pulmonary arterial pressure, which may be one of the main causes of chronic pulmonary hypertension in COPD patients (ie, out of proportion) with otherwise moderate but not severe airflow obstruction. ${ }^{21}$ Therefore, continuous oxygen flow titration is needed to avoid desaturations that cannot be predicted on the basis of a simple exercise test in the hospital.

Fourth, development or worsening of hypoxemia during sleep is well documented in COPD patients and is associated with cardiac arrhythmia and, eventually, pulmonary hypertension. ${ }^{22}$ Nocturnal desaturation also occurs in approximately a quarter of COPD patients with diurnal $\mathrm{P}_{\mathrm{aO}_{2}}$ $>60 \mathrm{~mm} \mathrm{Hg}$, and is not necessarily evaluated with nocturnal oximetry. ${ }^{23}$

Indeed, even in the case of this evaluation, the first step is to perform the examination without oxygen, and then to repeat it with oxygen. With the $\mathrm{O}_{2}$ Flow Regulator, both tests could be performed in one night, because if $\mathrm{S}_{\mathrm{pO}_{2}}$ remains above the target $90 \%$, the $\mathrm{O}_{2}$ Flow Regulator will not deliver any oxygen, which could be eventually added in case of desaturation, as established by the algorithm. In this case important information will be available for the clinician to set the appropriate oxygen flow.

Last, as clearly illustrated in the present study, the $\mathrm{O}_{2}$ Flow Regulator may save RT time when an exercise program should be set for a COPD patient, and at the same time make the appropriate adjustments in the case a clinician is not present.

\section{Limitations}

Our selection of a 15-min constant-work-rate test may be criticized, but compared to the incremental maximal, symptom-limited testing induces more severe hypoxemia and therefore would have resulted in substantially fewer patients qualifying for LTOT. ${ }^{14}$ Cutaneous oxygen saturation measurement (ie, pulse oximetry) has several advan- 


\section{Pilot Study of a New Device to Titrate Oxygen Flow}

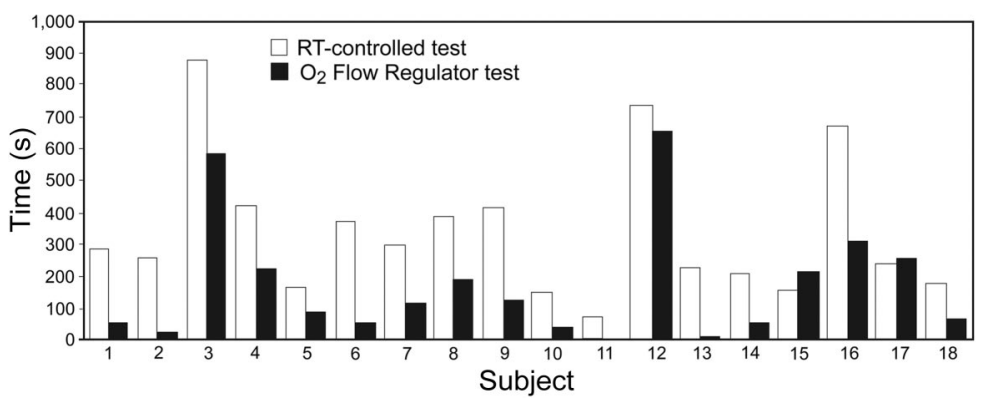

Fig. 4. Time spent below the target $\mathrm{S}_{\mathrm{pO}_{2}}$ during exercise tests (in 18 subjects) in which the supplemental oxygen flow was manually titrated by the respiratory therapist (RT) or automatically titrated by the $\mathrm{O}_{2}$ Flow Regulator.

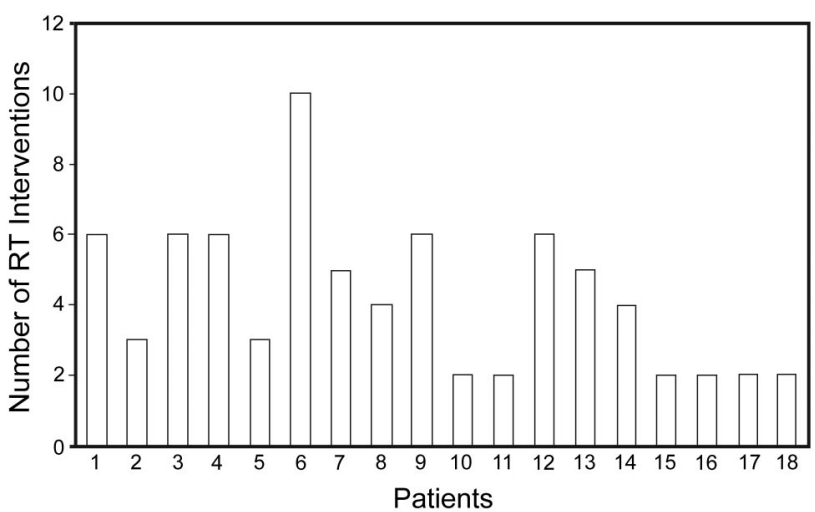

Fig. 5. Number of manual oxygen-flow titrations during exercise tests (in 18 subjects) in which the oxygen flow was manually titrated by the respiratory therapist to maintain the target $\mathrm{S}_{\mathrm{pO}_{2}}$.

tages in the estimation of arterial oxyhemoglobin, but also some disadvantages: it is less accurate than direct measurement of arterial blood, particularly in patients with carboxyhemoglobin $>4 \%$ or methemoglobin $>1 \%$. However, we excluded such individuals. ${ }^{3}$ Also, the target $\mathrm{S}_{\mathrm{pO}_{2}}$ we chose $(94 \%)^{15}$ may be considered too high in usual clinical practice, and a lower $\mathrm{S}_{\mathrm{pO}_{2}}$ may also be acceptable.

\section{Conclusions}

The $\mathrm{O}_{2}$ Flow Regulator safely and effectively titrated oxygen flow during a constant-work-load exercise test, and may save RT time during pulmonary rehabilitation exercise. We see potential for the $\mathrm{O}_{2}$ Flow Regulator in many daily life situations where the oxygen flow should be reduced or augmented. Safety and patient satisfaction with the $\mathrm{O}_{2}$ Flow Regulator need to be examined in a larger prospective study.

\section{REFERENCES}

1. Nocturnal Oxygen Therapy Trial Group. Continuous or nocturnal oxygen therapy in hypoxemic chronic obstructive lung disease; a clinical trial. Ann Intern Med 1980;93(3):391-398.
2. Medical Research Council Working Party. Long-term domiciliary oxygen therapy in chronic hypoxic cor pulmonale complicating chronic bronchitis and emphysema. Lancet 1981;1(8222):681-686.

3. American Thoracic Society. Standards for diagnosis and care of patients with COPD (COPD). Am J Respir Crit Care Med 1995; 152(Suppl 5):S77-S121.

4. Siafakas NM, Vermeire P, Pride NB, Paoletti P, Gibson J, Howard $\mathrm{P}$, et al. Optimal assessment and management of chronic obstructive pulmonary disease (COPD). The European Respiratory Society Task Force. Eur Respir J 1995;8(8):1398-1420.

5. Rabe KF, Hurd S, Anzueto A, Barnes PJ, Buist SA, Calverley P, et al. Global strategy for the diagnosis, management, and prevention of COPD. GOLD Executive Summery. Am J Respir Crit Care Med 2007;176(6):532-555.

6. Celli BR, MacNee W; ATS/ERS Task Force. Standards for diagnosis and treatment of patients with COPD: a summary of the ATS/ERS position paper. Eur Respir J 2004;23(6):932-946.

7. Skwarski K, MacNee W, Wraith PK, Sliwinski P, Zielinski J. Predictor of survival in patients with COPD treated with long-term oxygen therapy. Chest 1991;100(6):1522-1527.

8. Soguel Schenkel N, Muralt BB, Fitting JW. Oxygen saturation during daily activities in COPD. Eur Respir J 1996;9(12):25842589.

9. Sliwinski P, Lagosz M, Gorecka D, Zielinski J. The adequacy of oxygenation in COPD patients undergoing long-term oxygen therapy assessed by pulse oximetry at home. Eur Respir J 1994;7(2):274278

10. Morrison D, Skwarski KM, MacNee W. The adequacy of oxygenation in patients with hypoxic COPD treated with long-term domiciliary oxygen. Respir Med 1997;91(5):287-291.

11. Ries AL, Bauldoff GS, Carlin BW, Casaburi R, Emery CF, Mahler DA, et al. Pulmonary rehabilitation. Joint ACCP/AACVPR evidence-based clinical practice guidelines. Chest 2007;13(Suppl 5): $4 \mathrm{~S}-42 \mathrm{~S}$

12. Turner SE, Eastwood PR, Cecins NM, Hillman DR, Jenkins SC. Physiological responses to incremental and self-paced exercise in COPD. Chest 2004;126(3):766-773.

13. Spence DP, Hay JG, Carter J, Pearson MG, Carverley PM. Oxygen desaturation and breathlessness during corridor walking in COPD: effect of oxitropium bromide. Thorax 1993;48(11):1145-1150.

14. Carlin BW, Clausen JL, Ries AL. The effects of exercise testing on the prescription of oxygen therapy. Chest 1994;106(2):361-365.

15. Carone M, Patessio A, Appendini L, Purro A, Czernicka E, Zanaboni $\mathrm{S}$, Donner $\mathrm{CF}$. Comparison of invasive and non invasive saturation monitoring in prescribing oxygen during exercise in COPD patients. Eur Respir J 1997;10(2):446-451.

16. Nici L, Donner C, Wouters E, Zuwallack R, Ambrosino N, Bourbeau $\mathrm{J}$, et al. American Thoracic Society/European Respiratory Society 


\section{Pilot Study of a New Device to Titrate Oxygen Flow}

statement on pulmonary rehabilitation. Am J Respir Crit Care Med 2006;173(12):1390-1413.

17. ATS Committee on Proficiency Standards for Clinical Pulmonary Functional Laboratories. ATS statement: guidelines for six-minute walk test. Am J Respir Crit Care Med 2002;166(1):111-117.

18. Guyatt GH, Nonoyama M, Lacchetti C, Goeree R, McKim D, HeelsAnsdell D, Goldstein R. A randomized trial of strategies for assessing eligibility for long-term domiciliary oxygen therapy. Am J Respir Crit Care Med 2005;172(5):573-580.

19. Plant PK, Owen JL, Elliot MW. One year period prevalence study of respiratory acidosis in exacerbation of COPD: implications for the provision of noninvasive ventilation and oxygen administration. Tho$\operatorname{rax} 2000 ; 55(7): 550-554$.
20. Emtner M, Porszasz J, Burns M, Somfay A, Casaburi R. Benefits of supplemental oxygen in exercise training in nonhypoxemic COPD patients. Am J Respir Crit Care Med 2003;168(9):10341042.

21. Fletcher EC, Luckett RA, Miller T, Costarangos C, Kutka N, Fletcher JG. Pulmonary vascular hemodynamics in chronic lung disease patients with and without oxyhemoglobin desaturation during sleep. Chest 1989;95(4):157-166.

22. Flick MR, Block AJ. Nocturnal vs diurnal cardiac arrhythmias in patients with COPD. Chest 1979;75(5):8-11.

23. Fletcher EC, Miller J, Divine GW, Fletcher JG, Miller T. Nocturnal oxyhemoglobin desaturation in COPD patients with arterial oxygen tensions above 60mmHg. Chest 1987;92(4):604-608.

This article is approved for Continuing Respiratory Care Education credit. For information and to obtain your CRCE

(free to AARC members) visit

RCJournal.com 